\title{
Epistemological Reasons for Lack of Science in Ancient China
}

\author{
Li Ma \\ School of English Studies, Xi'an International Studies University, Xi'an, China \\ Email: mali@xisu.edu.cn
}

Received 3 July 2015; accepted 12 September 2015; published 15 September 2015

Copyright (C) 2015 by author and Scientific Research Publishing Inc.

This work is licensed under the Creative Commons Attribution International License (CC BY). http://creativecommons.org/licenses/by/4.0/

(c) (i) Open Access

\section{Abstract}

The purpose of this study was to identify the epistemological reasons for lack of science in ancient China. The study reveals a striking contrast between China and the West in terms of epistemologies concerning scientific development. In the beginning, the term "science" is defined through some illustrations which can help illuminate its essential features. Then, the study distinguishes the differences between Chinese and Western epistemologies about scientific development. The differences lie mainly in four aspects-distinct patterns of research methodology, reasoning and truth-seeking, and dissimilar understanding of the relationship between man and nature. Through discussion on each aspect, the elements which scientific development requires while Chinese were lacking in are diagnosed. A lot of typical examples, including ancient Greek and Chinese philosophies, modern Western scientists, and "subject-object dichotomy" vs. "man being an integral part of nature" offer convincing data for the study.

\section{Keywords}

Epistemology, Scientific Development, Reasoning, Truth-Seeking, Ethic-Oriented, Truth-Oriented

\section{Introduction}

When probing into the reasons why there was lack of science in ancient China, one would conceive of quite a few factors that may account.

Historically speaking, many methods of inquiry were developed during the Spring and Autumn Period (770-476 B.C.) and the Warring States Period (475-221 B.C.), but most of them were interrupted and never recovered until much later because of books burning by the First Emperor of Qin who unified the country around 221 B.C. This undoubtedly had a great impact not only on the development of research methodology, but also on the entire Chinese civilization [1]. 
Epistemologically speaking, under the far-reaching influence of such traditional Chinese doctrines as Taoism and Confucianism, Chinese are more holistic, intuitive, ethic-oriented, and inward when compared with Westerners.

Lin Yutang in his My Country and My People meticulously analyzed the epistemological cause of Chinese's failure to develop natural science. According to him, "The Chinese mind delights only in moral platitudes. Experimentation was never thought of, and no scientific method had been developed. The Chinese believe in flashes of common sense and insight and they depend largely upon their intuition for solving all nature's mysteries” [2].

This paper, intrigued by Lin's analysis, intends to discuss the reasons for lack of science in ancient China from an epistemological perspective. I will focus my argument on the contrasts between Chinese and Western epistemologies so as to pinpoint the elements which scientific development requires while Chinese were found lacking in.

\section{What Is Science?}

Instead of giving a simple definition to science, it may be more appropriate to illustrate what it is. Below are some elucidations from several sources:

Science is a method of learning about the physical universe by applying the principles of the scientific method, which includes making empirical observations, proposing hypotheses to explain those observations, and testing those hypotheses in valid and reliable ways [3].

Science is a way of acquiring knowledge. To do science, one must follow a specific universal methodology. The central theme in this methodology is the testing of hypotheses and the ability to make predictions. The overall goal of science is to better understand nature and our Universe [4].

Science is the process of gaining knowledge based on making repeated observations about nature in controlled conditions (experimentation) and attempting to explain what causes those observations (theorizing) through constructing hypotheses that can be tested experimentally. Science's only purpose is to gain knowledge [5].

Science is the synthesis of the systematic study of every aspect of our experience of reality, especially objective reality, usually with the aim of reducing it to a logically-consistent system of order [6].

From the above explanations, several ingredients can be detected about science. First, it is a way of acquiring knowledge. Second, the object of its study is nature or physical universe. Third, it involves scientific methodology. Finally, it aims at a logically-consistent system.

\section{Western Analytic Methodology vs. Chinese Holistic Methodology}

Every research method has its philosophical foundation. It covers anything dealing with ways of acquiring new knowledge, approaches taken to discover the facts, or methods designed to solve new problems [1]. Analytical methodology is characteristic of Westerners, while holistic methodology is featured by Chinese.

On the relationship between man and nature, "subject-object dichotomy”, an analytic methodology in Western cultural tradition manifests itself in the belief that in acquiring knowledge man stands for the subjective world while nature for the objective world [7]. Since nature alone is the cognitive object, it can be separated from man. In other words, human and nature exist independent of each other. Consequently, the advancement of natural science follows.

Greek culture is where science derived. The Greeks laid the foundation for natural science because the Greek mind was essentially an analytical mind [2]. Democritus’ philosophy is basically natural philosophy, reflecting upon the exterior nature. Pythagoras' philosophy is approximate to mathematics. Socrates, Plato, and Aristotle further differentiated man from nature.

Western philosophers in modern times, including Descartes and Bacon, approached philosophical theories from the perspective of natural science. Kant engaged himself in a kind of philosophical study which was actually based on natural science, especially mathematics and physics.

Just because of the failure to develop an analytic method, China has been backward in science. On the relationship between man and nature, Chinese cultural tradition applied the spirit known as "man being an integral part of nature”, a holistic methodology which led people to the integration of man and nature [7]. "Man being an integral part of nature” implies that nature coexists with man and, therefore, is not the isolated cognitive object 
in acquiring knowledge. Nature is closely bound with man's life. Naturally, men did not emphasize the study of so-called objective nature, but paid more attention to a state where nature and man corresponded with each other. As a result, the focus of Chinese culture has been on the discussions about man's spiritual activity and status instead of nature or natural science.

Holistic thinking is also expressly shown in the Calendar of Xia. According to the Calendar of Xia, the integration of heaven (universe), earth, and human is the only way of interpreting causes for any event [1]. This belief has several important characteristics: 1 ) Human activities operate within the entire life system (human, animals, trees), the life system operates within the lifeless system (material world as represented by earth), and these systems are regulated by universe (natural law as represented by heaven). 2) The coordination of these elements under universe is emphasized. Harmony and stability of the universe are dependent on the uniformity of these elements. 3) Maintaining the harmony of universe is the only way to gain successes of human activities.

\section{Western Logical Reasoning vs. Chinese Intuitive Reasoning}

As it has been revealed earlier in this paper, science aims at a logically-consistent system. So logic is greatly enhanced in the arena of science-it plays an important role in epistemology in that it provides a mechanism for extension of knowledge. As a byproduct of reasoning, logic provides prescriptions for it, that is, how people ought to reason. There are two patterns of human reasoning: rational and intuitive. The West has been canonizing rational scientific knowledge and depreciating intuitive religious knowledge, while the situation is vice versa in China [8].

\subsection{Deductive and Inductive Reasoning in Western Logic}

Since Western culture sets seeking truth as the highest goal, it is bound to lay emphasis on logical reasoning, and analyzing is sure to be the cognitive method of knowing the object by the subject within the Western "subjectobject dichotomy" framework. For one thing, the cognitive object is metaphysical matter, something beyond physical phenomenon. For another, seeking truth entails abstraction from phenomenon. So it is only through logical reasoning and analyzing that one can fulfill such process [7].

Aristotle's Organon lay the foundation of deductive reasoning, hence of the formal logic. An inference is deductively valid if and only if there is no possible situation in which all the premises are true and the conclusion false. The notion of deductive validity can be rigorously stated for systems of formal logic in terms wellunderstood notions of semantics.

Francis Bacon was the founder of inductive reasoning. Inductive validity requires us to define reliable generalization of some set of observations. The task of providing this definition may be approached in various ways, some less formal than others; some of these definitions may use mathematical models of probability. Induction is believed to be the way to scientific discoveries.

The concept of positivism can be traced back to the inductive reasoning of Francis Bacon. Positivism believes that there is an external world out there. We can learn the facts about the external world only through experimentation and manipulation [1]. Empirical observations are used to verify the scientific hypothesis. With the increase of the observations, the probability of the truth of the hypothesis will increase. Therefore, this is the only way to scientific discoveries, that is, observations are the prerequisite of a theory.

\subsection{Traditional Chinese Reasoning}

\subsubsection{Mohism}

Of all the ancient philosophers of the Zhou Dynasty, only Motse and Hanfeitse developed a style akin to cogent reasoning [2]. According to the Mohism, the three laws of reasoning for true knowledge are: 1) There must be a basis or foundation; 2) There must be a general survey; 3) There must be practical application. The second law is the first initiation of empirical method in the Chinese history. The first two laws have the similar characteristics of the scientific method. Five methods of inference are also illustrated: deduction, comparison, parallel, analogy, and induction.

Unfortunately, Mohism disappeared entirely at the end of the second century B. C. Three possible causes are identified [1]: 1) Its doctrines of universal love and anti-militarism were incompatible with the needs of the age of warfare. 2) Scientific research and philosophical speculation are not the priority during the age of warfare. 3) 
Confucianism and Mohism were all persecuted under the Chin Empire through books burning. Confucianism can recover immediately after Chin Empire because it preaches what wanted by the new rulers.

\subsubsection{Chinese Intuitive Reasoning}

Chinese "logic" is based on the Chinese conception of truth. Truth, according to the Chinese, can never be proved: it can only be suggested. "Tao, or truth, is that which we know not the matter of" [2]. Instead of relying on logic, which is never developed as a science, they rely on the perhaps healthier common sense.

Common sense takes the place of inductive and deductive reasoning in China. Nevertheless, the logic of common sense can only be applied to human affairs and actions; it cannot be applied to the solution of the riddles of the universe. Hence, in divining nature's mysteries and the secrets of the human body, the Chinese have to resort largely to intuition or intuitive reasoning [2]. Accordingly, Chinese traditional reasoning is mainly based on intuition. Intuition, being immediate insight of the mind, is obviously different from the scientific method of observation, experimentation, and verification [9].

Chinese scholar never descended to manual labor. Having a naive faith in the power of "intuition," the Chinese scholars went about explaining the mysteries of the human body and the universe to their own satisfaction. The whole science of Chinese medicines and physiology is based on the Taoist philosophy of the Five Elements-Gold, Wood, Water, Fire and Earth [2].

\subsubsection{Imagery}

Chinese concrete imagery always takes the place of abstract terminology which is essential in science. To say "How could I know what is going on his mind?" is not so effective as the Chinese "Am I a tapeworm in his belly?” Chinese thought always remains on the periphery of the visible world [2]. The profuseness of imagery and paucity of abstract terminology has an influence on the style of thought. On the one hand, it makes for vividness; on the other, it may easily degenerate into a senseless decorativeness without exact content. Such a style suffers from lack of exactness of expression. When dealing with abstraction - an important element in natural science study, that Chinese logic is practiced in a concrete way certainly seems insufficient.

\section{Western Truth-Oriented vs. Chinese Ethic-Oriented}

Western culture regards seeking truth as the final end of cognition. The purpose of knowing nature must be probing truth in order to guide people to change and conquer nature [7]. Ancient Greek philosopher Heraclitus claimed that wisdom lies in knowing the truth. In the Middle Ages, Saint Augustine argued that truth is above soul and reason. Francis Bacon put forward finding law of nature, i.e. truth by the scientific method of combining experimentation and reasoning. In Western culture, truth is above ethic and ethic submits to truth.

The concept of "man being an integral part of nature" in Chinese culture undoubtedly led to the orientation of ethic [7]. Ancient Chinese culture lacked in pure epistemology; cognition and seeking truth were not only bound but also affiliated with ethic and seeking good. This explains why some call Chinese philosophy as ethical philosophy. The Analects of Confucius is a book which concentrates on preaching benevolence with ethics as the gist. Mencius also built his epistemology on ethics.

\section{Western Outwardness vs. Chinese Inwardness}

In Western culture, according to Aristotle, man is a reasoning being. With such ideology, human reasoning is above anything else, by which we can know the surrounding world, discover the universe mysteries, and acquire the freedom of controlling and conquering the outside world.

In conflicting and struggling with nature, Westerners gradually formed the Weltanschauung that life is meaningful only through exploring, adventuring and expanding outward. They look upon knowledge acquiring, truth finding, scientific discovery, and nature conquering as the greatest pursuits in their life.

Chinese culture, starting with "man being an integral part of nature", emphasizes inward probing —a kind of personal tendency toward inward ethic — rather than outward expanding. Chinese aimed at adapting themselves to nature, thus achieving the harmony between inward and outward. Ancient Chinese accentuated personal inward culturing and placed the meaning of life on the inward. The Analects of Confucius thus advocated "Every day I examine myself in three aspects”. Chinese culture stresses self-examination and self-probing. When dealing with outward nature, Chinese strived for adjustment, harmony and unification, known as "man being an 
integral part of nature”.

\section{Conclusions}

Through comparing the epistemological differences between the West and China, it is safe for us to conclude that lack of science in ancient China can be attributed to distinct patterns of methodology, reasoning and truth-seeking, and dissimilar understanding of the relationship between man and nature.

However, it does not mean that there was no science at all in ancient China. In the first place, Chinese science is more technological and practical than Western science. Important inventions were not absent in China, but comparatively speaking there was a lack of systematic scientific theory. Even the world-famous Nine Chapters on the Mathematical Art is without a regular set of terminology or formulae. Secondly, compared with Western science, Chinese science was more closely corresponding with man. Chinese medicine differs from Western medicine in that based on "man being an integral part of nature" it displays the holistic view of man's life. Chinese astronomy differs from Western astronomy in that also based on "man being an integral part of nature" it was primarily closely associated with astrology, investigating the telepathy between heaven and man.

\section{References}

[1] Xu, Z.J. (2004) Ancient Chinese Philosophers on Methods of Inquiry. http://140.120.36.28/t/english01.htm

[2] Lin, Y.T. (2000) My Country and My People. Foreign Language Teaching and Research Press, Beijing.

[3] Glossary of Terminology (2004) http://www.coris.noaa.gov/glossary/glossary_l_z.html\#s

[4] Glossary of Terms (2004) http://www.geog.ouc.bc.ca/physgeog/physgeoglos/s.html

[5] http://www.sasked.gov.sk.ca/docs/chemistry/mission2mars/contents/glossary/s.htm

[6] (2006) Appendix A: Glossary of Terms. http://www.tomgraves.com.au/index.php

[7] Zhu, L.Y. and Wang, Z.F. (1998) Man Being an Integral Part of Nature-The Spirit of Chinese Aesthetic Culture. Shanghai Literature and Art Press, Shanghai.

[8] Hao, H.Z. (1997) Comprehension of Chinese People. Liaoning People’s Press, Shenyang.

[9] Chang, C. (1960) Chinese Intuitionism: A Reply to Feigl on Intuition. Philosophy East \& West, University of Hawaii Press, Hawaii, 35-49. http://ccbs.ntu.edu.tw/FULLTEXT/JR-PHIL/ew27130.htm 